\title{
Inpatients' and outpatients' satisfaction: The mediating role of perceived quality of physical and social environment
}

\author{
Cláudia Campos Andrade ${ }^{\mathrm{a}, *}$, Maria Luísa Lima ${ }^{\mathrm{a}}$, Cícero Roberto Pereira ${ }^{\mathrm{b}}$, \\ Ferdinando Fornara ${ }^{c, d}$, Marino Bonaiuto ${ }^{c, e}$ \\ a Instituto Universitário de Lisboa (ISCTE-IUL), CIS-IUL, Av. das Forças Armadas, 1649-026 Lisboa, Portugal \\ ${ }^{\mathrm{b}}$ Instituto de Ciências Sociais da Universidade de Lisboa (ICS), Lisboa, Portugal \\ ' Centro Interuniversitario di Ricerca in Psicologia Ambientale (CIRPA), Rome, Italy \\ ${ }^{\mathrm{d}}$ Università degli Studi di Cagliari, Cagliari, Italy \\ e Sapienza Università di Roma, Rome, Italy
}

\section{A R T I C L E I N F O}

\section{Article history:}

Received 1 February 2012

Received in revised form

4 August 2012

Accepted 14 January 2013

Available online 11 February 2013

\section{Keywords}

Hospital

Inpatients versus outpatients

Physical environment

Environmental quality perception

Satisfaction

\begin{abstract}
A B S T R A C T
This study analyses the processes through which the physical environment of health care settings impacts on patients' well-being. Specifically, we investigate the mediating role of perceptions of the physical and social environments, and if this process is moderated by patients' status, that is, if the objective physical environment impacts inpatients' and outpatients' satisfaction by different socialpsychological processes. Patients $(N=206)$ evaluated the physical and social environments of the care unit where they were receiving treatment, and its objective physical conditions were independently evaluated by two architects. Results showed that the objective environmental quality affects satisfaction through perceptions of environmental quality, and that patients' status moderates this relationship. For inpatients, it is the perception of quality of the social environment that mediates the relationship between objective environmental quality and satisfaction, whereas for outpatients it is the perception of quality of the physical environment. This moderated mediation is discussed in terms of differences on patients' experiences of health care environments.
\end{abstract}

(c) 2013 Elsevier Ltd. All rights reserved.

\section{Introduction}

The main goal of health facilities is to promote the users' wellbeing, and the technical and professional dimensions of those facilities are essential to reach that goal. At the same time there is a growing literature showing that the way hospitals are designed also matters significantly. Imagine you are in a hospital for a consultation. If you wait in a quiet and tidy room, with a view to green spaces, nice paintings on the wall, and comfortable seats, you are likely to feel well, expect good care, and be satisfied with the visit. Alternatively, if the waiting room is noisy and disorganized, with no windows, old posters on the walls and uncomfortable seats, it is likely that you will feel less positive, question the quality of care, and end up less satisfied with the health care service. This association between features of the physical environment and patients' well-being has been found in several studies (see Ulrich et al., 2008, for a review).

Typically those studies show the effect of a specific attribute of the health care physical environment (e.g., view from the

\footnotetext{
* Corresponding author. Tel.: +351210464017.

E-mail address: claudiarcandrade@gmail.com (C. Campos Andrade).
}

window, presence of plants) or the impact of some environmental changes (e.g., renovation) on patients' outcomes (e.g., overall satisfaction, stress) as if these relationships were per se selfevident. In fact, literature on health care environments has paid little attention to the mediating processes through which those relationships occur. The research presented in this paper was undertaken to investigate how the health care physical environment is related to well-being. Specifically, we tested if satisfaction with the care unit occurs because the physical environment and social environment are evaluated as having higher quality in hospital areas with more objective environmental quality. In other words, we examined whether the perceptions of patients on the quality of the physical and social environments mediate the relationship between the health care physical conditions and satisfaction with the care unit. In the next sections we will review the literature that focuses on the different associations implicated in this hypothesis.

1.1. From features of the physical environment to perceptions of the quality of health care environments

Several studies have demonstrated the impact of the spatial and physical conditions of hospital settings on the perceptions of 
the quality of the physical environment. Physical environment is defined as ambient, architectural or interior design features that are purely stimulus objects (Dijkstra et al., 2006; Harris et al., 2002) and that characterize the healthcare settings. Swan et al. (2003) found that patients recovering in appealing rooms rated their rooms significantly higher than did patients in typical rooms in the same hospital, and Leather et al. (2003) found that a relocated (and redesigned) waiting area originated more positive environmental appraisals, and greater reported environmental satisfaction than the traditional waiting area before relocation. In another study, Becker et al. (2008) compared patients' perceptions of health care quality before and after a dermatology outpatient practice moved from an older building, described as "traditional" in design and décor (and ranked by independent judges as the least attractive setting among six), to a new facility designed to create a highly attractive environment for patients. Patients in the new environment rated the waiting area as being more pleasant, more private, and less crowded than was true for the old environment.

These results show that the improved features of the health care physical environment have consequences on its perceived quality; but that is not the whole picture. These changes also have impact on the perception of the social environment of the care unit. For example, Hagerman et al. (2005) found that patients recovering in rooms with good acoustics considered the staff attitude to be much better than did patients treated in rooms with poor acoustics. The study of Swan et al. (2003) also found that patients in appealing rooms evaluate physicians more positively than patients in typical rooms in the same hospital.

Using photographs of 28 different waiting rooms, Arneill and Devlin (2002) asked participants to rate how they perceived the quality of care to be delivered in those healthcare settings. Results showed that perceived quality of care was greater for waiting rooms that were nicely furnished, well-lighted, contained artwork, and were warm in appearance, versus waiting rooms that had outdated furnishings, were dark, contained no art-work or poor quality reproductions, and were cold in appearance. The impact of the features of counseling office environments on people' perceptions has also been studied, revealing that, for example, softness/personalization and order are associated with perceptions of how bold, friendly, and qualified the therapist in the office was likely to be (Nasar and Devlin, 2011), and that the display of credentials is associated with therapists' qualifications and energy (Devlin et al., 2009).

In sum, research shows that the features of the health care settings' physical environment not only influence the appraisal of the physical environment, but also affect the perception of care and staff. This outcome is not surprising since the literature supports the idea that physical traces or cues left by occupants in their work and home environments may be used to form impressions about their traits or characteristics (e.g., Harris and Sachau, 2005; Gosling et al., 2002). In a health care setting, as Arneill and Devlin (2002) pointed out, the physical environment is the first impression that a patient receives. If the environment communicates that the doctors, nurses, and other staff care about its appearance and function themselves and design it with the patient in mind, then the patient enters the system with a positive image of the health care process and trusts that he/she will be well cared for in all other aspects.

These findings may also explain why the perceptions of the physical environment and social environment are often correlated. Fornara et al. (2006) found that in a low humanized hospital (which orthopedic care unit experts evaluated as low quality), inpatients and outpatients perceived lower spatial-physical comfort, as well as lower care for social and organizational relationships than did patients in medium- and high-humanized hospitals. This congruence between the quality of spatial-physical features and social-functional aspects was also found in the studies of Swan et al. (2003), Arneill and Devlin (2002), and Becker et al. (2008), already described in this paper.

\subsection{From perceptions of the quality of the health care environment to well-being}

A different group of studies has shown that both the perception of the quality of the hospital' physical and social environments predict patients' well-being. In other words, the quality of the healthcare setting from the users perspective (Gifford, 2002), and the quality of the social and organizational relationships in general, including the relationship with the staff (Irurita, 1999), are crucial for patients' satisfaction with the hospital experience. Harris et al. (2002) interviewed 380 discharged inpatients to identify environmental sources of satisfaction with the hospital, and, specifically, to determine the relative contribution of environmental satisfaction to overall satisfaction with the hospital experience. Environmental satisfaction, that is, satisfaction with interior design, architecture, housekeeping, privacy, and the ambient environment was perceived as a source of overall satisfaction, following nursing and clinical care. In order to explore the views of patients on how their perceived health, mood, and quality of life are affected by the ward physical environment, Rowlands and Noble (2008) interviewed patients with advanced cancer. Despite the fact that patients were informed previously that the purpose of the study was to assist in the redesign of the ward, the strongest theme that emerged was the importance of staff, in particular the nurses. Secondly, three major themes related to the physical environment appeared: the immediate environment, single versus multioccupancy rooms, and contact with the outside environment. Patients reported that the attitude, competence, and helpfulness of the staff create the atmosphere of the ward regardless of layout, furnishings, equipment and décor, but they also assumed that the physical environment has an effect on their mood and well-being.

Similarly, but using a questionnaire approach, and focusing on primary health care centers, Raposo et al. (2009) examined the dimensions of health care quality that predict patients' satisfaction. Perception of the quality and empathy of medical care was the stronger predictor of patient satisfaction, followed by the facility's quality.

These studies demonstrate that the evaluations of the physical environment and of the social environment are two important predictors of satisfaction with the health care service that might also influence mood and well-being. Specifically, it should be noted that what is common in studies that address the influence of both physical and social dimensions (see also Andaleeb et al., 2007; Gotlieb, 2002; Pilpel, 1996; Ziaei et al., 2011) is that normally perceptions of caregivers explain the larger part of variance of patients' satisfaction, but that the physical environment also has a statistically significant positive impact.

\subsection{How physical environment features lead to well-being: The mediating role of the perception of the hospital's quality of environment}

It has long been recognized that the health care physical environment affects patients' well-being. Reference can be made to the study of Dijkstra et al. (2008) who, using a scenario describing a possible hospitalization, found that a photo of a hospital room with indoor plants generated less perceived stress to participants than did a room with a painting of an urban environment on the wall. Further, Ulrich's (1984) well-known 
study showed that patients in a room with a view of everyday nature recovered more rapidly and with more emotional wellbeing (received fewer negative evaluative comments in nurses' notes) than did patients in similar rooms with a view of a brick wall. Studies mentioned earlier also show this connection. For example, Swan et al. (2003) found that appealing rooms result in more favorable patients' judgments of the hospital, stronger intentions to use the hospital again, and stronger intentions to recommend the hospital to others, than typical rooms, and Leather et al. (2003) found that the relocated waiting area was associated with improved mood, altered physiological state, and decrease of the selfreported stress scores compared with the traditional waiting area before relocation.

This relationship between health care physical environment and well-being is certainly complex. However, few studies have addressed the psychological processes through which it actually occurs. As described earlier, research has demonstrated that the physical and social environments are the two major dimensions by which patients perceive the quality of the health care environment. In addition, empirical results seem to support the links between these variables and objective physical environment features, as well as with patients' outcomes like satisfaction and emotional well-being. As a whole, this evidence suggests that the perceptions of the quality of the social and physical health care environments can be potential mediators in the relationship between the physical environment features and well-being, but this process was never explicitly tested. For example, using a series of hierarchical regression models, Fornara (2005) analyzed separately the factors (i.e., socio-demographics, objective quality of the physical environment, and the best indicators of perceived quality of hospital physical and social environments) predicting inpatients' and outpatients' satisfaction. Results showed that socio-demographic factors did not affect satisfaction, and the final models revealed that the significant effect of the objective quality of the physical environment became non-significant once the indicators of hospital perceived quality were added. The author raised the hypothesis that the perceptions of quality could play a mediating role, but that hypothesis has not yet been tested.

Therefore, in this study we tested the hypothesis that the relationship between physical environment features and satisfaction is mediated by the perception of the quality of the physical environment and of the social environment (see Fig. 1). Our model proposes that "objective" physical environment features elicit patients' "subjective" evaluations of the physical and social environments. These perceptions, in turn, will lead to overall satisfaction. In other words, the more the health care setting is humanized, patient-centered, and high-quality design, the higher should be the perception of the quality of the physical

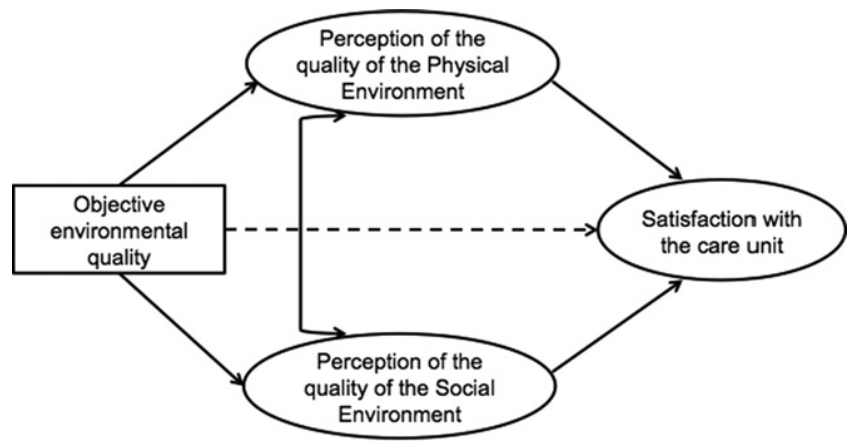

Fig. 1. Predicted relationship between the objective environmental quality and satisfaction, mediated by the perceptions of the quality of the physical and social environments. environment and of social environment of the care unit. In turn, the higher the perceived quality of the care units' physical and social environments, the higher should be the patients' satisfaction.

This model is also supported on some theoretical models concerning a different kind of settings, i.e., the residential places. According to the theoretical model of residential satisfaction from Amérigo (1995), Amérigo and Aragonés (1997) the objective attributes of the residential environment, once they have been evaluated by the individual, become subjective, giving rise to a certain degree of satisfaction. This theoretical framework emphasizes the difference between objective and subjective attributes and distinguishes between the perception of social and physical aspects of the environment as predictors of residential satisfaction, which is similar to what our model proposes in relation to health care settings. In her studies, Amérigo investigated which perceived environment quality indicators and socio-demographic characteristics predict residential satisfaction and how residential satisfaction influenced certain behaviors, but her theoretical model of residential satisfaction was never fully tested.

\subsection{Does the situation matter? Inpatients' versus outpatients' views of environmental quality}

Being in a hospital as an inpatient or an outpatient is a very different experience. Outpatients are theoretically in a healthier condition, are less dependent on medical and nursing care, spend much less time in the health care setting, and have less contact with doctors, nurses and administrative staff than do inpatients. Inpatients, in turn, stay for at least one night in the hospital, are supposedly in a more delicate condition, and are more dependent on nursing care. These are only some reasons to predict that, for example, perceptions of the hospital physical and social environments may have different relevance for inpatients' and outpatients' satisfaction.

Studies on the impact of physical environment on well-being and satisfaction, as well as research on physical and social dimensions of the perception of quality, have been carried out both in inpatient (e.g., Swan et al., 2003) and outpatient (e.g., Leather et al., 2003) health care settings. However, the relative weight of these dimensions on inpatients' and outpatients' satisfaction has not often been compared.

An exception is the study of Fornara (2005), who tested separately the predictors of inpatients' and outpatients' satisfaction, and found that spatial-physical comfort and relations with staff predicted inpatients' satisfaction, whereas outpatients' satisfaction was predicted only by spatial-physical comfort. These results give us a clue that the way objective environmental quality lead to satisfaction might be different between inpatients and outpatients. However, the whole process from objective environmental quality to perceptions of quality, and from perceptions of quality to satisfaction (Fig. 1) was not tested. Moreover, when separated models are used, one cannot know if the differences found between the groups are statistically significant.

In the present study we will use a methodological strategy that allow overcoming these limitations by exploring whether inpatients and outpatients differ with respect to the impact of physical environment features on perceptions of physical and social environments, and/or with respect to the impact of those perceptions of the physical and social environment on satisfaction with the care unit. In sum, considering the differences of inpatients and outpatients in terms of their hospital experience, not only we hypothesize that the relationship between the hospital physical environment and patients' satisfaction is mediated by perceptions of the physical and social environments, but also that this process might be moderated by patients' status. 


\section{Overview of the study}

In order to shed light on the relationship between the health care physical environment and patients' satisfaction, the present study investigated the mediating role of the way the physical and social environments are perceived. Additionally, we investigated if this process is moderated by patients' status, that is, if there are any differences between inpatients and outpatients.

Inpatients and outpatients from four different hospitals were asked to evaluate the physical and social environments of the care unit where they were receiving treatment at the moment they were contacted. The physical environments of those care units were also independently evaluated by two architects, in order to get a measure of "objective" environmental quality. This evaluation is important because patients' assessments are a product of individual interpretations subject to the influence of variables such as personality, experience, mood, stress or, in this particular case, perceptions of the social environment.

The study followed most of the theoretical and methodological challenges identified by Winkel et al. (2011). The proposed contextual model includes the role of the physical and social environments to explain individuals' experience in health care environments and tests some modeling processes, such as the processes by which the physical environment operates on satisfaction (quality perception of physical and social environments as mediating variables), and the variables that alter the impact of physical environment on satisfaction (patients' status as a moderator variable). With regard to methodological advances, this study focused not only on representativeness of the participants, but also on the variability of the settings and environmental characteristics (data were collected in four different hospitals with very different physical features). Moreover, we did not rely only on subjective measurement of the environment, but also on the "objective" assessments of environmental conditions provided by trained experts.

Technical environmental assessments employ mechanical equipment or other physical means to produce reading of environmental quality (Gifford, 2002), such as measurement of the noise level in decibels (e.g., Hagerman et al., 2005). However, not every physical attribute can be measured through mechanical monitoring equipment. Therefore, other studies have used the judgments of experts to obtain an objective assessment of the overall quality of the physical environment (e.g., Durán-Narucki, 2008). These studies assume that experts have the required knowledge and training to judge the quality of specific attributes - such as the materials, maintenance or colors of the floors, walls and ceilings - even though there is no measuring instrument capable of providing a numerical quantification of its quality. On the other hand, observer-based environmental assessments are measures of the quality of the environment as it is experienced by its users, and are based on their human (and lay) perceptual skills (Gifford, 2002). In this study, the objective quality of the care units' physical environment was assessed by trained experts and the users' perception of environmental quality was assessed by patients.

\section{Method}

\subsection{Participants and settings}

Two hundred and six patients participated in this study, 122 (59.5\%) of whom were women. Participants were contacted in inpatient areas and outpatient areas of orthopedic units from four different hospitals. The hospitals were selected to obtain diversity of the settings and participants, but only in orthopedic units to provide consistency across unit type. In short, data was collected in eight different health care settings: four inpatient areas, and four outpatient areas. The sample was composed of 110 (53.4\%) inpatients, hospitalized in an orthopedic care unit $\left(M_{\text {days }}=7.54\right.$; $S D=10.55$; Mode $=2$ days), and 96 (46.6\%) outpatients that were waiting for a consultation in the waiting room of an outpatient area $\left(M_{\min }=81.86 ; S D=61.12 ;\right.$ Mode $\left.=60 \mathrm{~min}\right)$.

The age of the subjects ranged from 18 to 88 years with a mean age of 55 years and a standard deviation of 17 years, and the sample of inpatients was significantly older $(M=59.41, S D=$ 16.30) than the sample of outpatients $(M=50.71, S D=16.97)$ $(F(1,204)=14.055, p<.001)$. In terms of level of education, 28 patients $(13.7 \%)$ had university-level education, 42 (20.5\%) finished secondary school, $35(17.1 \%)$ had completed 9 years of school, 15 (7.3\%) 6 years of school, and 85 (41.5\%) completed only 4 years of school or less. The low education of the sample is related with the fact that orthopedic problems are more prevalent in older ages. A chi-square test showed that education level is not equally distributed among inpatients and outpatients (Chisquare $(4)=23.264, p<.001, V=.337$ ). More specifically, more inpatients had only 4 years of school or less $(n=62)$, compared to outpatients $(n=23)$. The majority of patients were married ( $n=133,64.9 \%), 35$ (17.1\%) were single, and 37 (18.0\%) were separated, divorced or widowed. On average, patients reported they go to a hospital 4.8 times a year. No differences were found in terms of sex, marital status or number of visits to hospitals by year between inpatients and outpatients.

In sum, the samples of outpatients and inpatients are similar in most of the socio-demographic characteristics, except as regards the age and the level of education (two variables highly correlated, $r=.53, p<.001)$. As a result, the effect of age will be controlled.

\subsection{Measures}

We used one questionnaire for detecting patients' assessments, and one observation grid for collecting the architects' objective evaluation of the hospital physical environment features.

\subsubsection{Questionnaire for patients}

Measures were collected using a self-report questionnaire. Perception of the quality of hospital environment was assessed by the PHEQIs (Andrade et al., 2012), namely the Care unit \& In-/ Out-patient (waiting) area Scale (which regards the perceived quality of spatial-physical aspects of the hospital care unit) and the Social-functional features Scale (which regards the perceived quality of social-functional aspects). Items are defined as sentences that express environmental evaluations (e.g., "In this in-patient/ waiting area the quality of furnishings is good"), and responses are made on 5-point Likert-type scales (from 0 "totally disagree" to 4 "totally agree"). Each scale contains both positive (i.e., indicating the presence of quality) and negative (i.e., indicating the absence of quality) items, in order to control for response set.

The Care unit \& In-/Out-patient (waiting) area scale has four factors of environmental quality perception: Spatial-physical comfort ( 6 items, $\alpha=.83$ ), Orientation ( 4 items, $\alpha=.73$ ), Quietness (2 items, $\alpha=.64$ ), and Views and lighting ( 3 items, $\alpha=.66$ ); and the scale on Social-functional features has two factors, Care for social and Organizational relationship (6 items, $\alpha=.76$ ), and Privacy (3 items, $\alpha=.59$ ).

Satisfaction with the care unit was measured through the following four questions (Raposo et al., 2009): "Considering your global experience in this care unit, in general, how satisfied are you?", "To what extent does this care unit meet your 
expectations?", "To what extent does this care unit meet your needs?", and "Imagine now an Orthopedic care unit, perfect in all its aspects. How far do you think this care unit is from a perfect care unit?". Responses to these items were recorded on a 11-point scale ranging, respectively, from (0) "very unsatisfied" to (10) "very satisfied", from (0) "not at all" to (10) "totally", from (0) "not at all" to (10) "totally", and from "very distant" to "very close".

\subsubsection{Instrument for experts' objective evaluation}

Objective evaluation of the physical environment was done by two independent judges with a theoretical background in architectural design issues, who observed in detail the physical places where patients were contacted to participate in the study: four outpatient areas and four inpatient areas. Judges were trained to use the checklist and informed that in their evaluation they should consider the function and objectives of the place and the needs of the users, and not their own general preferences. Data were collected by means of an expert checklist that covered the same issues as the Care unit \& In-/Out-patient (waiting) area PHEQI scale (see Fornara et al., 2006), except as regards the Quietness dimension. The checklist has 29 items related with specific features of the physical environment (e.g., number of places to sit; quality of the furniture). The more abstract items were combined with specific attributes that should be taken into account (e.g., to rate the quality of the furniture judges should consider materials, shape, style, stability, adequacy for different users, and back and arm support). Items were rated from 0 to 4 with the categories of inadequate, minimal, satisfactory, good, and excellent. Interjudge agreement was strong, $\mathrm{r}(276)=.66$, $\mathrm{p}<.01$.

\subsection{Procedure}

The study was approved by the "Central Administration of the Health System" (ACSS) Portuguese public institute, which helped us to identify and to contact each of the four hospitals that took part of the study. We then sent a letter to the administration of the hospitals explaining the purpose of the study and asking for a meeting with members of the administration and with the directors of the orthopedic care units. We explained every detail of the method, and we stressed the importance of the collaboration of the healthcare professionals in identifying the patients that could participate. The members of the administration of the four hospitals and the directors of all care units approved the study and accepted to collaborate.

Data was collected between October and December 2009. There were no inclusion criteria other than age (above 18) and willingness to participate in the study. Outpatients were contacted by the first author in the waiting area before consultation, and inpatients were contacted in their hospital rooms.

As outpatients filled the questionnaire in the waiting room (and before consultation), they were included in the final sample only if they had been in that care unit at least once, to ensure that they would have sufficient information to evaluate both the physical and social environment of the care unit, as well as satisfaction with the service. Because of that, 13 outpatients were excluded from the sample. From those who were kept in the sample, $63(66.3 \%)$ had been in that outpatient care unit more than four times, $24(23.5 \%)$ had been two or three times, and only $8(8.4 \%)$ had been there once before.

Inpatients were in the hospital for at least one day. Taking into account the inclusion criteria, potential participants were identified by the healthcare professionals. All patients identified were asked to take part of the study. When inpatients accepted to participate, the questionnaire was left with them and collected the next day. From the inpatients that accepted to participate, $50(45.5 \%)$ had been in that care unit before. More specifically, $15(30.0 \%)$ of them had been more than 4 times, 12 (24.0\%) had been two or three times, and 23 (46.0\%) had been once.

Researchers were informed that neither the outpatient nor the inpatient care units were subject to changes in terms of physical conditions or in terms of the core of the staff team in the recent years. All patients (inpatients and outpatients) were informed of the nature and purpose of the study, and confidentiality was assured. It was emphasized that their decision to participate in the study would not affect their care, and that hospital personnel would not see the information provided. When patients did not have the physical abilities to read or to answer the questionnaire on their own, data were collected through an interview that lasted approximately $30 \mathrm{~min}$. The instructions clearly asked patients to respond to the questionnaire focusing on the particular care unit where they were at the moment.

\subsection{Data analysis}

The hypotheses were tested on a series of structural equation models (SEM) using the AMOS 17 software (Arbuckle, 2006). SEM allow to specify and estimate models of relationships between measured (observed) and latent variables (constructs that are not directly measured) (MacCallum and Austin, 2000). Our independent variable "objective environmental quality" is an observed variable, whereas perception of the quality of physical environment, perception of the quality of social-functional environment and satisfaction with the care unit were defined as latent variables with four, two and four indicators, respectively (see Fig. 1). The objective is to obtain the most parsimonious summary of the relationships between the variables that accurately represents the associations observed in the data (Weston and Gore, 2006). Specifying a model including latent variables is important because it allows estimating the parameters that represent the relationships between the variables while controlling for error of measurement (Bollen, 1989). Models were calculated from the variance-covariance matrix of the indicators that was obtained using pairwise deletion for missing data. Initially, we estimated the parameters of the model for the whole sample considering inpatients and outpatients. We then repeated the procedure using multi-group analyses. In all the analyses, standard errors of parameters were estimated according to the method of maximum likelihood. To evaluate the global adjustment quality of the model we considered the CFI (Comparative Fit-Index) and GFI (Goodness-of-Fit Index) above.90, the $\chi^{2} /$ degrees of freedom ratio around 2, and the RMSEA (Root Mean Square Error of Approximation) below .05 as indicating a good fit of the model to the data (e.g., Schumacker and Lomax, 1996).

\section{Results}

\subsection{Preliminary analysis}

\subsubsection{Objective evaluation of the physical environment}

The mean score between the two experts' evaluations of each inpatient area and outpatient area was computed (see Table 1) in order to use a more reliable score of objective environmental quality, which was used as the independent variable in the mediation analyses. Results show that hospitals' orthopedic care units vary in terms of objective physical environment quality. Hospitals 1 and 2 have inpatient and outpatient areas with lower physical environmental quality than do hospitals 3 and 4 . 


\subsubsection{Descriptive statistics and reliability analysis}

Table 2 presents the descriptive statistics and Table 3 presents the correlations between the indicators used in the proposed model. In general, results show that patients are satisfied with the care units and have positive perceptions of the quality of its physical and social environments. Specifically, inpatients are more satisfied $(F(1,203)=12.25, p<.001)$ and perceive higher levels of physical

Table 1

Means of the experts' evaluations of the health care settings.

\begin{tabular}{lllll}
\hline & $H 1$ & $H 2$ & $H 3$ & $H 4$ \\
\hline Inpatient area & $\mathbf{2 . 2 1}$ & $\mathbf{1 . 3 5}$ & $\mathbf{2 . 4 8}$ & $\mathbf{2 . 9 9}$ \\
Comfort & 2.46 & 1.06 & 2.34 & 2.77 \\
Orientation & 1.75 & 0.75 & 2.13 & 2.70 \\
Views and lighting & 2.42 & 2.25 & 2.97 & 3.50 \\
Outpatient area & $\mathbf{2 . 2 6}$ & $\mathbf{1 . 9 4}$ & $\mathbf{2 . 9 4}$ & $\mathbf{3 . 1 0}$ \\
Comfort & 1.56 & 1.60 & 2.36 & 3.31 \\
Orientation & 2.86 & 2.14 & 3.00 & 3.29 \\
Views and lighting & 2.37 & 2.08 & 3.45 & 2.70
\end{tabular}

Note: $H 1$ to $H 4=$ Hospital 1 to Hospital 4 . Values in bold compose the variable "objective environmental quality".

Table 2

Means and standard deviations of the variables.

\begin{tabular}{lrl}
\hline & $\begin{array}{c}\text { Inpatients } \\
\text { Mean }(S D)\end{array}$ & $\begin{array}{l}\text { Outpatients } \\
\text { Mean }(S D)\end{array}$ \\
\hline Satisfaction with the care unit & & \\
Sat 1 & $8.09(2.02)$ & $6.92(2.04)$ \\
Sat 2 & $8.14(2.14)$ & $7.03(2.23)$ \\
Sat 3 & $8.05(2.31)$ & $7.27(2.30)$ \\
Sat 4 & $7.33(2.51)$ & $6.37(2.69)$ \\
& & \\
Perception of the quality of the physical environment & $2.74(1.03)$ & $2.17(1.00)$ \\
Comfort & $3.04(0.96)$ & $2.67(0.94)$ \\
Orientation & $2.90(1.33)$ & $3.15(0.93)$ \\
Quietness & $3.18(0.94)$ & $2.26(1.23)$ \\
Views and lighting & & \\
Perception of the quality of the social-functional environment & \\
Care for social and organizational relationships & $3.02(0.91)$ & $2.80(0.87)$ \\
Privacy & $3.17(0.88)$ & $2.16(1.11)$ \\
Objective environmental quality & $2.21(0.54)$ & $2.46(0.46)$ \\
\hline
\end{tabular}

and social environment quality, particularly with regard to comfort $(F(1,204)=16.40, p<.001)$, orientation $(F(1,202)=7.58, p<.01)$, views and lighting $(F(1,204)=37.00, p<.001)$ and privacy $(F(1,200)$ $=51.24, p<.001)$, than do outpatients. All the correlations are positive, ranging from weak to moderate, which indicates that they are measuring different constructs, avoiding any multicolinearity issues.

In order to check the construct validity of the proposed measurement model we conducted a confirmatory factor analysis (CFA) (Bollen, 1989). In this model, we specified three conceptual latent variables (i.e., perceived quality of physical environment, perceived quality of social environment, and satisfaction) that were allowed to correlate. In order to guarantee the statistical identification of the models, the factorial loading of one of the indicators of each latent variable was constrained at 1.00. Results showed a good fit to the data: $\chi^{2}(32, N=206)=55.73, p<.01, \chi^{2}$ । $\mathrm{df}=1.74, \mathrm{CFI}=.98, \mathrm{GFI}=.95$, RMSEA $=.06$, and factorial loadings were high on their respective factor (varying from .42 to .95). These results were compared to an alternative measurement model in which all items loaded on a general factor, meaning that all items measure only one latent variable. Result for this model showed a poor fit to data $\left(\chi^{2}(35, N=206)=229.31\right.$, $\left.p<.001, \chi^{2} / \mathrm{df}=6.55, \mathrm{CFI}=.83, \mathrm{GFI}=.76, \mathrm{RMSEA}=.16\right)$. Thus, the proposed measurement model fits better than does the alternative one, $\Delta \chi^{2}(3)=173.58, p<.001$, supporting the construct validity of the proposed measurement model.

\subsection{Mediation analyses}

To test the hypothesis that the relationship between objective environmental quality and satisfaction is mediated by the perceived quality of both physical and social environments we followed the procedures commonly recommended for the analysis of mediation using structural equations models (e.g., Kenny and Judd, 1984).

Results show that the total effect of objective environmental quality on satisfaction (corresponding to the effect of objective environment before taking in to account the physical environment and social-functional environment perceived quality in the model) is significant $(\beta=0.22, p<.01)$, which means that the greater the level of objective environmental quality, the greater the patients' satisfaction with the care unit. As one can see in Fig. 2, the relationship

Table 3

Correlation matrix of the items.

\begin{tabular}{|c|c|c|c|c|c|c|c|c|c|c|c|}
\hline & (1) & $(2)$ & (3) & $(4)$ & $(5)$ & $(6)$ & (7) & $(8)$ & (9) & $(10)$ & $(11)$ \\
\hline \multicolumn{12}{|l|}{ Satisfaction with the care unit } \\
\hline Sat $1(1)$ & & $.86^{* * * *}$ & $.79^{* * * *}$ & $.71^{* * * *}$ & $.41^{* * * *}$ & $.47^{* * * *}$ & .17 & $.34^{* *}$ & $.49^{* * * *}$ & .12 & $.37^{* * * *}$ \\
\hline Sat $2(2)$ & $.90^{* * * *}$ & & $.83^{* * * * *}$ & $.68^{* * * *}$ & $.43^{* * * *}$ & $.42^{* * * *}$ & .06 & $.33^{* *}$ & $.44^{* * * *}$ & .15 & $.35^{* *}$ \\
\hline Sat $3(3)$ & $.81^{* * * k *}$ & $.81^{* * * *}$ & & $.71^{* * * * *}$ & $.31 * *$ & $.27^{* *}$ & .05 & $.21^{*}$ & 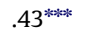 & .12 & $.24^{*}$ \\
\hline Sat $4(4)$ & $.74^{* * * * *}$ & $.77^{* * \cdots * k}$ & $.73^{* * * *}$ & & $.38^{* * * *}$ & $.29^{* * *}$ & .11 & .20 & $.37^{\text {**ok }}$ & .24 & $30^{* *}$ \\
\hline \multicolumn{12}{|c|}{ Perception of the quality of the physical environment } \\
\hline Comfort (5) & $.35^{\text {*k*k }}$ & $.37^{* * * * *}$ & $.37^{* * * *}$ & $.49^{* * * *}$ & & $.50^{* * * * *}$ & .19 & $.54^{* * * * *}$ & $.50^{* * * k}$ & .24 & $.63^{* * * *}$ \\
\hline Orientation (6) & .15 & $.21^{*}$ & .09 & $.30^{* * k}$ & $.38^{* * * *}$ & & $.34^{* *}$ & $.42^{* * * *}$ & $.55^{* * * *}$ & .12 & $.42^{* * * *}$ \\
\hline Quietness (7) & $.22^{*}$ & $.24^{*}$ & .16 & $.32^{* *}$ & $.46^{* * * *}$ & $.37^{* * * *}$ & & .20 & $.32^{* * *}$ & .18 & .08 \\
\hline Views and lighting (8) & .12 & .17 & .13 & $.23^{*}$ & $.46^{* * * *}$ & $.31^{* * * *}$ & $.47^{* * * *}$ & & $.51^{* * * * *}$ & .13 & $.60^{* * * *}$ \\
\hline \multicolumn{12}{|c|}{ Perception of the quality of the social-functional environment } \\
\hline $\begin{array}{l}\text { Care for social and organizational } \\
\text { relationships (9) }\end{array}$ & $.50 * * * *$ & $.53 * * *$ & $.45^{* * * *}$ & $.48^{* * * * *}$ & $.41^{* * * *}$ & $.28^{* * *}$ & $.37^{* * * * *}$ & $.44^{* * * *}$ & & $.48^{* * * *}$ & $.44^{* * * *}$ \\
\hline Privacy $(10)$ & .11 & .16 & .12 & .14 & $.30^{* * *}$ & $.23^{*}$ & $.22^{*}$ & $.36^{* * * * *}$ & $.32^{* *}$ & & .17 \\
\hline Objective environmental quality (11) & $.21^{*}$ & $.23^{*}$ & $.23 *$ & $.36^{* * * *}$ & $.62^{* * * *}$ & $.30^{* * *}$ & $.29 * *$ & .17 & $.26^{* * *}$ & $.23^{* *}$ & \\
\hline
\end{tabular}

Note: Correlation matrix's diagonal was omitted. Values above the diagonal are correlations for outpatients, and values below the diagonal are correlations for inpatients.

${ }^{*} p<.05$.

$* * * 0.01$.

**** $p<.001$. 


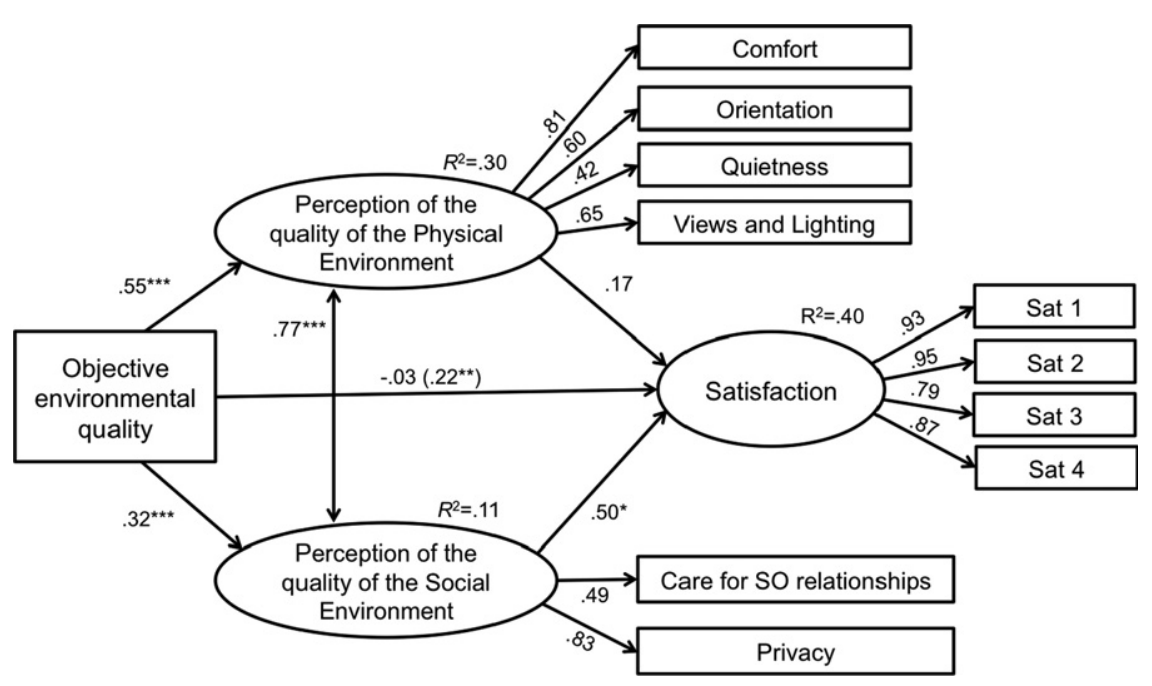

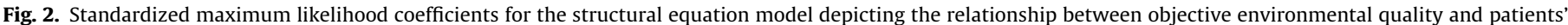

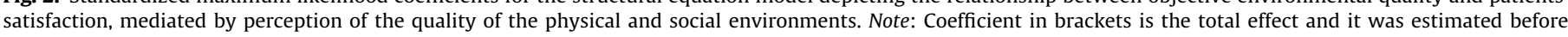
considering the two mediators in the model. ${ }^{*} p<.05,{ }^{* *} p<.01,{ }^{* * *} p<.001$.

between objective environmental quality and the two types of environmental quality perception are positive and significant, i.e., greater objective environmental quality implies greater perception of the quality of both the physical environment $(\beta=.55, p<.001)$ and of the social-functional environment $(\beta=.32 p<.001)$. On the other hand, the effect of the perceived quality of social-functional environment on well-being is significant $\left(\beta_{\mathrm{PQSFE}-S a t}=.50, p<.05\right)$, whereas the perceived quality of physical environment does not reliably predict satisfaction. Finally, the direct effect of objective environmental quality on satisfaction is not significant, suggesting that the effect of objective quality on well-being could be mediated by perceptions of the quality of the environment. The correlation residual between physical environment quality perception and social-functional environment quality perception is strong and significant $(r=.77, p<.001)$. Of greater importance for the mediation test, the analysis of the decomposition of the effects of objective environmental quality on satisfaction indicates that only the perceived quality of social-functional environment mediates this relationship (Mediated effect $=.16 ; Z_{\text {Sobel }}=1.93, p<.05$, one-tailed).

The three independent latent variables accounted for $40 \%$ of the variance in satisfaction and analyses of the goodness-of-fit indices for the proposed model show a good fit to the data: $\chi^{2}(39, N=206)=$ 80.51, $p<.001, \chi^{2} / \mathrm{df}=2.06, \mathrm{CFI}=.97, \mathrm{GFI}=.94$, RMSEA $=.07$. These results show the construct validity of the measures we used to test our predictions.

As differences between inpatients and outpatients were found in terms of age (inpatients are significantly older), we conducted a supplementary analysis in which we estimated the same mediation model, now controlling for the effect of age. Although results show that age has a significant effect on the perception of the quality of the physical environment, the relationships between the variables objective environmental quality, perceptions of the quality of the physical and social environments, and satisfaction with the care unit remained virtually the same. In other words, the effect of age do not affect the process by which objective environmental quality results in more satisfaction with the care unit, through perceptions of the quality of the hospital environment. More specifically, again, only the perceived quality of social-functional environment mediates this relationship (Mediated effect $=.16 ; Z_{\text {Sobel }}=1.84, p<.05$, one-tailed). Therefore, the potential differences between inpatients and outpatients regarding the effect of objective environmental quality on satisfaction by means of perceptions of the quality of the hospital environment are not due to differences in terms of age.

\subsection{Inpatients vs. outpatient}

We analyzed the invariance of the structural model in order to test whether the social-psychological process going from objective quality of the physical environment to satisfaction occurs in the same way for both inpatients and outpatients. In other words, we tested if the mediation process between objective quality of the physical environment and satisfaction is moderated by patients' status using multi-group analysis.

First, we calculated a baseline model where we allowed the structural parameters to be freely estimated between groups of inpatients and outpatients. The measurement error variances of the two indicators of perceived quality of the social environment were constrained to equality across groups for purposes of statistical identification of the factor. The goodness-of-fit for this model is good, $\chi^{2}(79, N=206)=168.40, p<.001, \chi^{2} / \mathrm{df}=2.13, \mathrm{CFI}=.93, \mathrm{GFI}=.88$, RMSEA $=.07$, showing that the proposed model fits well the data (see Figs. 3 and 4). For both inpatients and outpatients, objective environmental quality predicts the perceived quality of the physical environment and the perceived quality of the social-functional environment. Moreover, for inpatients only the relationship between the perception of the quality of the social-functional environment and satisfaction is positive and significant, whereas for outpatients only the relationship between the perception of the quality of the physical environment and satisfaction is positive and significant.

As one can see in Table 4, which shows the decomposition of the effects of objective environmental quality on well-being, the total effect of objective environmental quality on well-being is significant and greater than that of the direct effect both for inpatients and outpatients. Moreover, results show that the relationship is mediated by the perceived quality of the social-functional environment for inpatients (Mediated effect $=.24 ; Z_{\text {Sobel }}=1.51, p<.07$, onetailed), whereas for outpatients the relationship is mediated by the perceived quality of the physical environment (Mediated effect $=.50 ; Z_{\text {Sobel }}=2.11, p<.05$, one-tailed).

In a second phase, we constrained the parameters of the structural model to equality between inpatients and outpatients. Results indicate that the fit of the constrained model is not so good as the baseline model $\left(\chi^{2}(84, N=206)=179.416, p<.001\right.$; $C F I=.92, G F I=.70, R M S E A=.07)$. In fact, there is a reliable difference between these models, $\Delta \chi^{2}(5)=11.01, p=.05$, indicating that, as predicted, the situation of patient moderated the meditating role of the perceived quality of environment. 


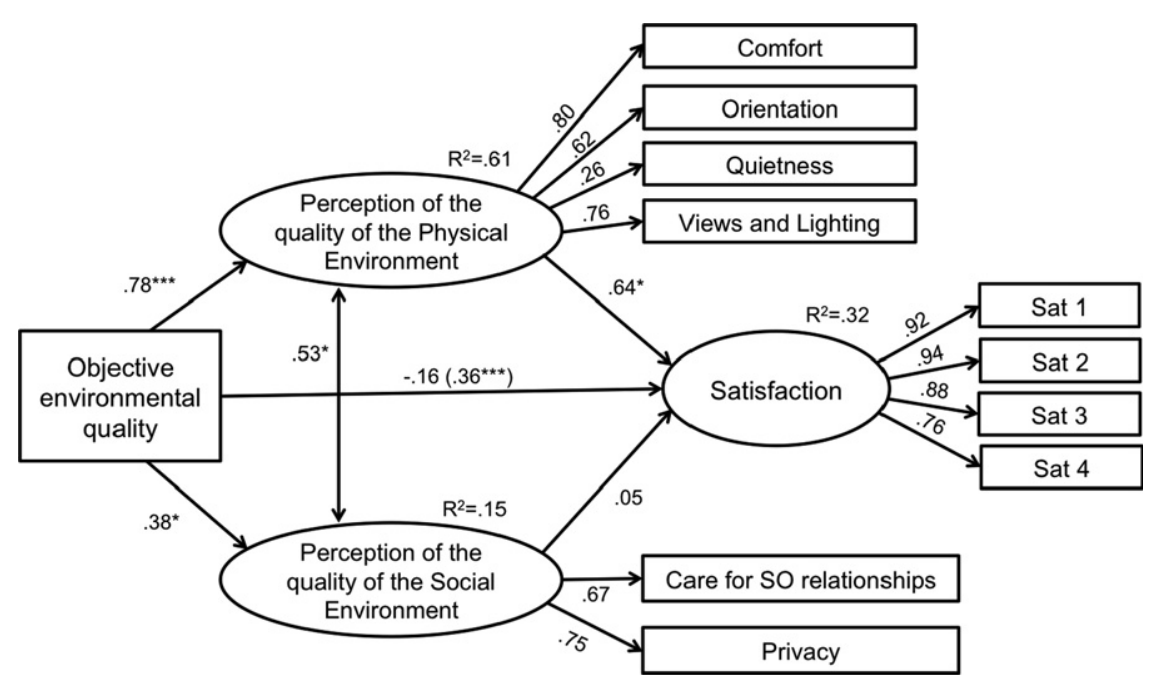

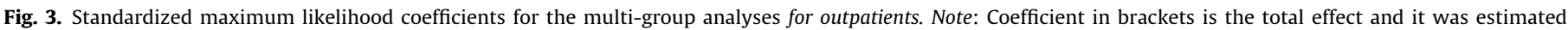
before considering the two mediators in the model. ${ }^{*} p<.05,{ }^{* *} p<.01,{ }^{* * *} p<.001$.

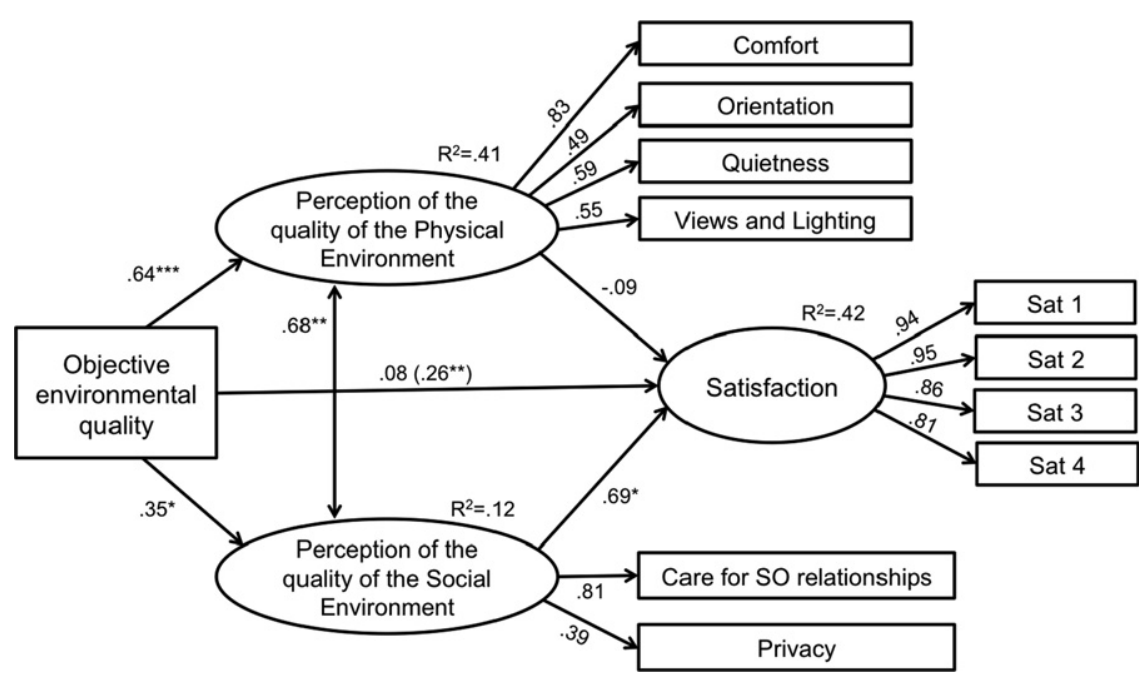

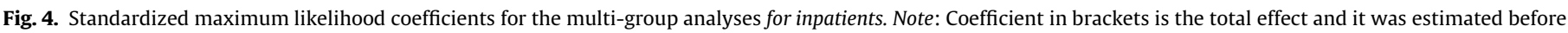
considering the two mediators in the model. ${ }^{*} p<.05,{ }^{* *} p<.01,{ }^{* * *} p<.001$.

Table 4

Decomposition of the effects of objective environmental quality on satisfaction, by group of patients.

\begin{tabular}{|c|c|c|c|c|}
\hline & \multirow{2}{*}{$\begin{array}{l}\text { Total } \\
\text { effect }\end{array}$} & \multicolumn{2}{|l|}{ Indirect effects through } & \multirow{2}{*}{$\begin{array}{l}\text { Direct } \\
\text { effect }\end{array}$} \\
\hline & & $\begin{array}{l}\text { Perception of the } \\
\text { quality of the physical } \\
\text { environment }\end{array}$ & $\begin{array}{l}\text { Perception of the quality } \\
\text { of the social-functional } \\
\text { environment }\end{array}$ & \\
\hline Outpatients & $.36^{\text {**ak }}$ & $.50^{*}$ & .02 & $\begin{array}{l}-.157 \\
(p=.447)\end{array}$ \\
\hline Inpatients & $.26^{* * *}$ & .06 & $.24^{*}$ & $\begin{array}{l}.008 \\
(p=.575)\end{array}$ \\
\hline
\end{tabular}

Note: Indirect effects were calculated according to the Sobel's test.

$$
\begin{aligned}
& { }^{*} p<.05 . \\
& { }^{* *} p<.01 . \\
& { }^{* * * *} p<.001 . \\
& { }^{\dagger} p<.07 .
\end{aligned}
$$

Additionally, in order to identify what the specific paths are moderated by the patients' status; we first estimated a model constraining the parameters of the effects of objective environmental quality on the perceived quality of the physical environment and on the perceived quality of the social-functional environment. Results showed that the fit of this model is not reliably different from the baseline $\left(\Delta \chi^{2}(2)=4.59, p=.10\right)$, indicating that the patients' status did not moderate these relationships. Then, we estimated other model in which we constrained the effects of the perceptions of the quality of the physical and social-functional environments on satisfaction, first both of them, and then one at a time. The results showed that the fit of the baseline is significantly better than the fit of the constrained model, $\Delta \chi^{2}(2)=7.30, p<.05$, indicating that the patient's status moderate the effects of the perceptions of the quality of the hospital environment on satisfaction. More specifically, we found that is the effect of the perceived quality of the social-functional environment on satisfaction, $\Delta \chi^{2}(1)=6.841, p<.01$, more than the effect of the perceived quality of the physical environment, $\Delta \chi^{2}(1)=3.739, p=.053$, that differs between inpatients and outpatients.

\section{Discussion}

The influence of the surrounding physical environment on the way people behave, feel and think is a longstanding topic of 
research and has implications for health care environments. Studies have shown that the health care physical environment affects patients' well-being in several ways, but little attention has been paid to the underlying mechanisms. The current study fills this gap by testing the general hypothesis that the relationship between the health care physical environment conditions and satisfaction with the care unit is mediated by perceptions of the quality of physical and social environments. In addition, we examined whether this process is moderated by the patients' status, that is, if it occurs differently for patients that are hospitalized over the course of a few days (inpatients) and patients that are only waiting for a consultation (outpatients).

Direct (unmediated) and indirect (mediated) relationships involving objective environmental quality, perceptions of the quality of physical and social environments, and satisfaction were tested through structural equation modeling, and moderation of patients' status (i.e., inpatients vs. outpatients) was tested by multi-group analyses. Results confirmed the hypothesis that health care physical environment conditions affect satisfaction through the perception of environmental quality. That is, in health care settings with higher quality in terms of physical conditions patients are more satisfied because their perceptions of the environment of the care unit are more positive. Analyses with the total sample (inpatients and outpatients pooled) showed that the relationship between health care physical environment conditions and satisfaction is mediated by the perception of the quality of the social-functional environment. Specifically, objective environmental quality predicts the perception of the quality of the physical environment (in terms of aspects related with spatial-physical comfort, orientation, quietness, views and lighting) and of the social environment (in terms of aspects related with social and organizational relationships, and privacy). However, only the perception of the quality of the social-functional environment affects patients' satisfaction. The same results were found when controlling for age, which is a variable that distinguishes our samples of inpatients and outpatients, meaning that the differences found are not due to differences in terms of age. Although the relationships observed between the variables of this model have already been studied by a large number of authors, no study had as yet proposed an holistic model construing these relationships in terms of a mediation process.

Moreover, multi-group analyses showed that objective environmental quality predicted satisfaction throughout different processes depending on patients' status. For both inpatients and outpatients, objective environmental quality predicts the perception of the quality of both the physical and social environments. However, for inpatients (as for the total sample), it is the perception of the quality of the social environment that mediates the relationship between objective environmental quality and satisfaction, whereas for outpatients it is the perception of the quality of the physical environment. This means that patients' status moderated the process linking objective environmental quality and satisfaction. Inpatients' satisfaction is affected by the way they perceive relationships with staff and organization of the care unit, whereas outpatients' satisfaction is chiefly affected by how good they perceive the physical environment to be.

We might wonder why these differences were found. It is plausible that inpatients' satisfaction is mostly affected by perceptions of social environment because, compared to outpatients, these patients are especially dependent on medical and nursing care. In fact, inpatients are directly and continuously embroiled in an interpersonal relationship with the staff and operational processes of the care unit. Additionally, their priority and their primary concerns are disease relief and a complete recovery, so they can return home in good health. Accordingly, health professionals, the organization of the service, and privacy are crucial, which consequently explains that inpatients' feeling of satisfaction is mostly explained by their perception of the quality of the social-functional environment. This result does not exclude the possibility that the physical environment of the inpatient area directly or indirectly can influence other relevant patients outcomes not included in this study. For example, previous research showed that the quality of the physical environment has an impact on physiological parameters, emotional state, recovery time, and stress (e.g., Dijkstra et al., 2008; Hagerman et al., 2005; Ulrich, 1984). In addition, it can be also possible that for these patients the influence of the perceived quality of the physical environment on satisfaction is mediated by their perceptions about the social environment.

For outpatients, in contrast, it is the perceived quality of the physical environment that predicts satisfaction. Following the previous reasoning, these patients are often in better health and less in need of health professionals' care than are inpatients. Consequently outpatients may be more open to considering other dimensions of health care service when evaluating their satisfaction, including the quality of the physical environment. What we found somewhat unexpected was the absence of a significant impact of the social environment on outpatients' satisfaction, since the literature shows that the social environment tends to be a crucial factor. An explanation for this result could be that outpatients were contacted in the waiting area, before the doctor consultation (since it would be very difficult to have outpatients participating after the consultation). So, it could be possible that our study had depicted a "first impression" of the care unit, conveyed basically by the physical environment (at the moment patients had only been in contact with the administrative workers). However, only patients who were in the care unit for at least the second time were selected, so they could use their previous experience to make their evaluations. In fact, $90 \%$ of them had been before in the same care unit two or more times. Moreover, in this study quality of the "social-functional environment" was not defined exclusively as the quality of the relationship with doctors and nurses, but staff in general, and includes the perceptions about other aspects such as the organization of the service and privacy issues. Considering all this, the argument that outpatients' perceptions of social environment do not affect satisfaction because they answered the questionnaire before consultation becomes unsatisfying. The result that only perceived quality of the physical environment predicts outpatients' satisfaction is not new (Fornara, 2005), which gives us additional confidence to infer that for outpatients - who often go to quick consultations to manage minor ailments or to request for a renewal of a prescription - the comfort and the appearance of the care unit setting have a particular impact.

The moderation by patients' status demonstrates the complexity of the mechanisms connecting physical environment and patients' well-being. However, it must be stressed that it is not the effect of the objective physical environment on perceptions of quality that differs between inpatients and outpatients, but rather the contributions of perceived quality of physical and social environment to satisfaction. Nevertheless, these findings corroborate that patients' satisfaction can be enhanced by improving the hospital physical conditions, which has important implications for health care services planning, design, and maintenance.

We believe it is important to draw attention to another finding, even if it is not directly related to our hypothesis. Results showed that inpatients perceive higher levels of physical environmental quality than do outpatients, despite the fact that inpatient areas were generally evaluated by architects as having lower quality than were outpatient areas. The same difference tends to occur in relation to the social environment, but in this case there is no objective assessment against which to compare.

This paradoxical result may be interpreted within the cognitive theory of stress (Lazarus and Folkman, 1984). This theory 
states that the appraisal of a relationship between the person and the environment as irrelevant, benign or stressful depends on the interpretation of its significance to well-being (primary appraisal), and of the coping options available (secondary appraisal). In a hospital setting, inpatients might supposedly be more vulnerable to stress than outpatients, not only because they might be in poor health and more physically and psychologically impaired, and so with less resources to deal with the demands, but also because they might actually need to deal with more sources of stress than do outpatients. For example, besides all the illness-related demands, inpatients need to adapt to a strange and uncomfortable environment for which they often have little control (for example, virtually all inpatients who participated in this study were accommodated in multiple rooms). More than being in a waiting room for some hours, inpatients necessarily have to experience the hospital room and care unit as if it was their "home", since they spend at least one night in the hospital. However, they might also be more prompt to reappraise or to cope with this specific external demand-the conditions of the physical environment. On the one hand, in fact, the physical conditions of the inpatient area are not amenable to be changed by the patients; on the other hand, inpatients might need to engage in coping with other - more "relevant" - aspects of the situation which they are going through (e.g., dealing with pain and incapacitation, developing adequate relationships with professional staff, preparing for an uncertain future, etc.; Moos and Tsu, 1977). Thus, inpatients - more than outpatients - might use an emotion-focused coping (Lazarus and Folkman, 1984) directed at changing (not the physical conditions, but) the meaning of the physical conditions. According to the Taylor's theory of Cognitive Adaptation (e.g., Taylor, 1983; Taylor et al., 1983; Taylor and Brown, 1988), it is plausible that inpatients may develop unrealistic positive perceptions of the physical environment, which could lower their emotional distress, and help them to cope better with other stressful aspects of the hospital experience. For example, inpatients may use cognitive strategies that enable them to tolerate, accept, and minimize the non ideal hospital' physical environment by making comparisons to hypothetically worse situations, by highlighting its benefits, or by maintaining that they are coping very well with the actual conditions. Such cognitive adaptation strategies would result in more positive evaluations of the inpatient area's physical conditions. Regarding the tendency for overestimation of the social environment (although we do not have the objective data to compare), we can make reference to the study of Baillie (2009), who interviewed patients and nurses in order to investigate patients' dignity in acute hospital settings, how it is promoted, and threatened. Most of the patients described adopting an attitude of acceptance and using humor to counteract threats to dignity (e.g., lack of privacy, curt or authoritarian staff behavior), which seemed to make them feel more comfortable. Some have also explicitly referred to developing good relationships with staff as a way to have a positive impact on how staff related to them. Baillie's study seems to demonstrate that patients promote their own dignity through their attitudes and ability to rationalize the situation, in relation to both the physical and the social environments.

Additional support to this idea is given by the fact that, in general, inpatients evaluate the quality of the physical and social environments of the inpatient area as significantly better than do visitors and staff (e.g., Devlin, 1995), meaning that patients tend to somehow adjust their expectations and modulate their attitudes. Therefore, future research could focus on identifying the role of (different sources of) stress and coping on how patients deal with their experience in healthcare facilities (see Ulrich, 1991). Lastly, and more pragmatically, it would also be plausible that inpatients could fell pressured by normative concerns to express positive opinions, fearing that health professionals could identify them. Consequently, they may have provided answers that they believed were desirable.

The high correlation between perceptions of the physical and social environment is also important to emphasize. This association might result from a bi-directional influence between these perceptions. The perception that the physical environment is neat, well maintained, and attractive may influence the perceptions of social environment in a positive fashion, reflecting that staff is concerned with patients' general well-being, so they invest time and money to provide patients with good conditions. Patients may also infer that the service is well organized, and that health care staff like their workplace and thus take good care of it. On the other hand, if staff is kind and caring, and if patients feel their privacy is assured, they will look more positively on the physical environment. Future studies should disentangle this relationship. Is it mostly the perception of the social environment that influences perception of physical environment or does this influence occur in both directions? This question remains to be addressed in the literature.

In fact, although the results reported here support our hypotheses, this study has an important limitation: its correlational nature. The correlational design weakens the evidence in support of the direction of the relationship between perceptions of environment and well-being. In fact, the proposed model is based on the hypothesis that there is a process that runs from perception of environmental quality to satisfaction. These results, however, do not exclude the possibility that satisfaction also affects environmental quality perception, in a bi-directional way. Other limitations relate to the fact that we had no indicator for objective quality of the social environment. Although the objective of the study was to investigate the process from objective quality of physical environment to well-being, a hard measure of the quality of the social environment would provide a more comprehensive picture.

This study provided some answers but also many additional challenging questions, which confirms that there is much more to investigate regarding the role played by physical environmental features of the hospital on patients' well-being. Our research extends beyond earlier studies because it gives a contribution to the understanding of how the process occurs for different types of patients. The present study provided evidence for one indirect way through which the physical environment affects patients' satisfaction (mediated by environmental quality perception) and demonstrated how this process works differently depending on the patients' status. This study suggests that hospitals can use the physical environment to promote patients' perceptions of quality and satisfaction with the services. More specifically, particular care should be provided so that the physical environments of outpatient care units are comfortable, well designed, and wellmaintained. Further, staff members of inpatient care units should be aware of their great impact on patients' well-being.

Future research on the relevance of the health care physical environment for well-being will profit from an increasing focus on the psychological processes that intervene between the physical environment and the person and that adequately take into account the physical and social contexts in their objective and subjective components.

\section{Acknowledgements}

This research was supported by a PhD Grant (SFRH/BD/43452/ 2008) from the Portuguese Foundation for Science and Technology awarded to the first author. The authors would like to thank 
the hospitals administrators for approving this study and are grateful to the patients for agreeing to participate. Special thanks to Ann Sloan Devlin for her precious feedback on a previous draft of this manuscript.

\section{References}

Amérigo, M. (1995). Satisfacción residencial. Un análisis psicológico de la vivienda y su entorno. Madrid, España: Alianza Editorial.

Amérigo, M., Aragonés, J.I., 1997. A theoretical and methodological approach to the study of residential satisfaction. Journal of Environment Psychology 17, 47-57.

Andaleeb, S.S., Siddiqui, N., Khandakar, S., 2007. Patient satisfaction with health services in Bangladesh. Health Policy and Planning 22, 263-273.

Andrade, C., Lima, M.L., Fornara, F., Bonaiuto, M., 2012. Users' views of hospital environmental quality: validation of the perceived hospital environment quality indicators (PHEQIs). Journal of Environmental Psychology 32, 97-111.

Arbuckle, J.L. (2006). Amos (Version 7.0) [Computer Program]. Chicago: SPSS.

Arneill, A., Devlin, A.S., 2002. Perceived quality of care: the influence of the waiting room environment. Journal of Environmental Psychology 22, 345-360.

Baillie, L., 2009. Patient dignity in an acute hospital setting: a case study. International Journal of Nursing Studies 46, 23-37.

Becker, F., Sweeney, B., Parsons, K., 2008. Ambulatory facility design and patients' perceptions of healthcare quality. Health Environments Research \& Design Journal 1 (4), 35-54.

Bollen, K.A., 1989. Structural Equations with Latent Variables. John Wiley \& Sons, New York.

Devlin, A.S., 1995. Staff, patients, and visitors: responses to hospital unit enhancements. In: Nasar, J.L., Grannis, P., Hanyu, K. (Eds.), Proceedings of the 26th annual conference of the Environmental Design Research Association. EDRA, Oklahoma City, OK, pp. 13-117.

Devlin, A.S., Donovan, S., Nicolov, A., Nold, O., Packard, A., Zandan, G., 2009. "Impressive?" Credentials, family photographs, and the perception of therapist qualities. Journal of Environmental Psychology 29, 503-512.

Dijkstra, K., Pieterse, M.E., Pruyn, A.T.H., 2006. Physical environmental stimuli that turn healthcare facilities into healing environments through psychologically mediated effects: systematic review. Journal of Advanced Nursing 56, 166-181.

Dijkstra, K., Pieterse, M.E., Pruyn, A.T.H., 2008. Stress-reducing effects of indoor plants in the built healthcare environment: the mediating role of perceived attractiveness. Preventive Medicine 47, 279-283.

Durán-Narucki, V., 2008. School building condition, school attendance, and academic achievement in New York City public schools: a mediation model. Journal of Environmental Psychology 28, 278-286.

Fornara, F., 2005. Users' evaluative responses to spatio-physical humanization: the case of hospital environments. In: Martens, B., Keul, A.G. (Eds.), Designing Social Innovation: Planning, Building, Evaluating. Hogrefe \& Huber, Gottingen (Germany), pp. 231-240.

Fornara, F., Bonaiuto, M., Bonnes, M., 2006. Perceived hospital environment quality indicators: a study of orthopaedic units. Journal of Environmental Psychology $26,321-334$.

Gifford, R., 2002. Environmental psychology: Principles and practice, 3rd. ed. Optimal Books, Canada.

Gosling, S.D., Ko, S.J., Mannarelli, T., Morris, M.E., 2002. A room with a cue: personality judgments based on offices and bedrooms. Journal of Personality and Social Psychology 82, 379-398.

Gotlieb, J.B., 2002. Understanding the effects of nurses on the process by which patients develop hospital satisfaction. Holistic Nursing Practice 16 (5), 49-60.
Hagerman, I., Rasmanis, G., Blomkvist, V., Ulrich, R.S., Eriksen, C.A., Theorell, T. 2005. Influence of coronary intensive care acoustics on the quality of care and physiological states of patients. International Journal of Cardiology 98, 267-270.

Harris, P.B., Sachau, D., 2005. Is cleanliness next to godliness? The role of housekeeping in impression formation. Environment and Behavior 37, 81-101.

Harris, P., McBride, G., Ross, C., Curtis, L., 2002. A place to heal: environmental sources of satisfaction among hospital patients. Journal of Applied Social Psychology 32, 1276-1299.

Irurita, V.F., 1999. Factors affecting the quality of nursing care: The patient's perspective. International Journal of Nursing Practice 5, 86-94.

Kenny, D.A., Judd, C.M., 1984. Estimating the nonlinear and interactive effects of latent variables. Psychological Bulletin 96, 201-210.

Lazarus, R.S., Folkman, S., 1984. Stress, Appraisal, and Coping. Springer, New York.

Leather, P., Beale, D., Santos, A., Watts, J., Lee, L., 2003. Outcomes of environmental appraisal of different hospital waiting areas. Environment and Behavior 35 (6), 842-869.

MacCallum, R.C., Austin, J.T., 2000. Applications of structural equation modeling in psychological research. Annual Review of Psychology 51, 201-226.

Moos, R., \& V. D. Tsu (1977). The crisis of physical illness: An overview. In R. Moos (Ed.), Coping with Physical Illness (p 3-22). New York: Plenum Medical.

Nasar, J.L., Devlin, A.S., 2011. Impressions of psychotherapists' offices. Journal of Counseling Psychology 58 (3), 310-320.

Pilpel, D., 1996. Hospitalized patients' satisfaction with caregivers' conduct and physical surroundings. Journal of General Internal Medicine 11, 312-314.

Raposo, M.L., Alves, M.A., Duarte, P.A., 2009. Dimensions of service quality and satisfaction in healthcare: a patient's satisfaction index. Service and Business $3,85-100$.

Rowlands, J., Noble, S., 2008. How does the environment impact on the quality of life of advanced cancer patients? A qualitative study with implications for ward design. Palliative Medicine 22, 768-774.

Schumacker, R.E., Lomax, R.G., 1996. A Beginner's Guide to Structural Equation Modeling. Lawrence Erlbaum Associates, Mahwah, NJ.

Swan, J., Richardson, L., Hutton, J., 2003. Do appealing hospital rooms increase patient evaluations of physicians, nurses, and hospital services? Health Care Management Review 28, 254-264.

Taylor, S.E., 1983. Adjustment to threatening events: a theory of cognitive adaptation. American Psychologist 38, 1161-1173.

Taylor, S.E., Wood, J.V., Lichtman, R.R., 1983. It could be worse: Selective evaluation as a response to victimization. Journal of Social Issues 39, 19-40.

Taylor, S.E., Brown, J., 1988. Illusion and well-being: a social psychological perspective on mental health. Psychological Bulletin 103, 193-210.

Ulrich, R.S., 1984. View through a window may influence recovery from surgery. Science 224, 420-421.

Ulrich, R.S., 1991. Effects of interior design on wellness: theory and recent scientific research. Journal of Health Care Interior Design 3, 97-109.

Ulrich, R.S., Zimring, C.M., Zhu, X., DuBose, J., Seo, H., Choi, Y., Quan, X., Joseph, A. 2008. A review of the research literature on evidence-based healthcare design. Health Environments Research and Design 1, 61-125.

Weston, R., Gore, P.A., 2006. A brief guide to structural equation modeling. The Counseling Psychologist 34, 719-751.

Winkel, G., Saegert, S., Evans, G.W., 2011. An ecological perspective on theory, methods, and analysis in environmental psychology: advances and challenges. Journal of Environmental Psychology 29 (3), 318-328.

Ziaei, H., Katibeh, M., Eskandari, A., Mirzadeh, M., Rabbanikhah, Z., Javadi, M.A. 2011. Determinants of patient satisfaction with ophthalmic services. BMC Research Notes 4 (7), 1-4. 